\title{
Micellar-Enhanced Highly Sensitive Reaction of Rare Earths with Xylenol Orange and Surfactants. Study of Reaction Conditions and Optimization of Spectrophotometric Method
}

\author{
Aleš Hrduč ka ${ }^{\dagger}$, Josef Havel ${ }^{\dagger}$, Carlos Moreno and Manuel Valiente ${ }^{\dagger}$ \\ Química Analitica, Universitat Autònoma de Barcelona, 08193 Bellaterra, Spain
}

\begin{abstract}
Reaction conditions in rare earths(RE)-Xylenol Orange(XO)-cationic surfactant ternary system were studied in detail. Conditional molar absorptivities up to $150000 \mathrm{mmol}^{-1} \mathrm{~cm}^{2}$ were reached. Highly sensitive spectrophotometric method for $15 \mathrm{RE}$ elements (REE) was evaluated under optimal conditions of $0.06 \mathrm{mmol} \mathrm{dm}^{-3} \mathrm{XO}, 0.6 \mathrm{mmol} \mathrm{dm}^{-3}$ cetylpyridinium bromide, and $0.01 \mathrm{~mol} \mathrm{dm}^{-3}$ acetate buffer of $\mathrm{pH} 4.50$. Calibration plots measured at 600,610 , and $620 \mathrm{~nm}$ were linear up to $5.5 \mu \mathrm{mol} \mathrm{dm}{ }^{-3}$ REE. The best detection limits of $0.04-0.20 \mu \mathrm{mol} \mathrm{dm}^{-3} \mathrm{REE}$ were reached at $610 \mathrm{~nm}$. In comparison with the previous results, the sensitivity of determination was increased and the range of knowledge of the mentioned ternary system was extended.
\end{abstract}

Keywords Spectrophotometry, rare earth elements-Xylenol Orange-surfactant, reaction condition

Interest in the lanthanoides as a result of work on nuclear fission and increasing commercial utilization of rare earth elements (REE) in general, as well as interest in their geological and environmental roles, has enhanced the need for rapid, sensitive methods of determination. In the spectrophotometric determination of REE, azo derivatives of chromotropic acid and reagents of triphenylmethane type are holding a prominent position. ${ }^{1}$ These typically low selectivity reagents are often used in pre- or post-column HPLC derivatization of metal species.

The reaction with Xylenol Orange (XO) in the presence of a surfactant was for the first time described by Svoboda and Chromý ${ }^{2}$ for lanthanum and cetylpyridinium bromide (CPB) and spectrophotometric determination of $0.56-5.6 \mu \mathrm{mol} \mathrm{dm}{ }^{-3} \mathrm{La}$ at $\mathrm{pH} 7.5$ was proposed. However, the influence of acidity was studied only in the range from $\mathrm{pH} 7$ to $\mathrm{pH} 11$ and the effects of CPB and buffer concentrations were not investigated. At higher $\mathrm{pH}$, from 8 to 9 , the mentioned ternary system was applied to REE determination by Otomo and Wakamatsu. ${ }^{3}$ The values of molar absorptivities estimated in neutral and slightly alkaline solutions were $92000 \mathrm{mmol}^{-1} \mathrm{~cm}^{2}(625 \mathrm{~nm})$ for $\mathrm{La}^{2}$ and approximately $100000 \mathrm{mmol}^{-1} \mathrm{~cm}^{2}(600-610 \mathrm{~nm})$ for REE in general. ${ }^{3}$ At pH 4, a substantially lower sensitivity, with molar absorptivity being at $45000 \mathrm{mmol}^{-1} \mathrm{~cm}^{2}(610 \mathrm{~nm})$, was stated for spectrophotometric determination of yttrium

\footnotetext{
$\dagger$ On leave from Department of Analytical Chemistry, Masaryk University, Kotlářská 2, 61137 Brno, Czechoslovakia.

\# To whom correspondence should be addressed.
}

with $\mathrm{XO}$ and $\mathrm{CPB} .{ }^{4}$ The results of REE chelatometric determination $^{5}$ where $\mathrm{XO}$ and $\mathrm{CP}$ chloride were used as an indicator have shown that the reaction in slightly acidic media of pH 5 can be far more sensitive, with molar absorptivity values between 86000 and $120000 \mathrm{mmol}^{-1}$ $\mathrm{cm}^{2}$ at $610-615 \mathrm{~nm}$. A more detailed study of the reaction in acidic media was not found, although it can be of specific interest because of the suppression of metal hydrolysis and probable application of lower reagent concentrations.

From the other reagents used for REE spectrophotometric determination, such as Arsenazo III, 4-(2-pyridylazo)resorcinol, and 5-bromo-2-(2-pyridylazo)-5-diethylaminophenol, the reaction with Chrome Azurol $\mathrm{S}$ in the presence of CPB was shown as the most sensitive. The detection limits ranged from 0.4 to $0.6 \mu \mathrm{mol} \mathrm{dm}^{-3}$ and molar absorptivities were $68000-81000 \mathrm{mmol}^{-1}$ $\mathrm{cm}^{2}{ }^{6}$

Usually, a special feature of the reaction in metal ionreagent-surfactant ternary system is the narrow interval of surfactant and reagent concentrations in which the reaction works. Because the information found in the literature was not sufficient, in the present work we have studied the interactions of 15 REE with XO in the presence of various cationic surfactants, aiming at systematic optimization of the analytical response of the mentioned ternary system. In this sense, the influence of various variables, i.e. acidity, reagent concentrations, nature of surfactant etc., has been investigated, the optimized conditions have been determined and improved features of spectrophotometric determination of the individual REE were shown. 


\section{Experimental}

\section{Reagents and solutions}

Nitrates (Y, La, Ce, Nd, Eu) and oxides (Gd, Tb, Dy, $\mathrm{Ho}, \mathrm{Er}, \mathrm{Tm}, \mathrm{Lu})$ of analytical grade purity and pure nitrates (Pr, Sm, Yb) were purchased from Fluka, Switzerland, except La (Merck, FRG) and Ce (Carlo Erba, Italy). Stock solutions of $2.5 \mathrm{mmol} \mathrm{dm}^{-3} \mathrm{REE}$ in $0.1 \mathrm{M} \mathrm{HNO}_{3}$ were standardized chelatometrically using $\mathrm{XO}$ as an indicator and acetate buffer of $\mathrm{pH} 4.2$ to 5.7. The optimum acidity was found experimentally for each determined element.

Xylenol Orange (Fluka, Switzerland) was used as received. Aqueous stock solutions of $1 \mathrm{mmol} \mathrm{dm}^{-3}$ concentration were prepared by weighing and acidified with several drops of $1 \mathrm{M} \mathrm{HNO}_{3}$. The absence of metal traces in XO reagent was proved by comparison of the spectra of $\mathrm{XO}$ solutions containing $0.1 \mathrm{mmol} \mathrm{dm}^{-3}$ EDTA and those of solutions without EDTA, both from pH 4 to $\mathrm{pH} 8$.

Aqueous stock solutions of $5 \mathrm{mmol} \mathrm{dm}^{-3}$ Septonex (1ethoxycarbonylpentadecyltrimethylammonium bromide) of pharmaceutical purity (Slovakofarma, Hlohovec, Czechoslovakia) and $3 \mathrm{mmol} \mathrm{dm}^{-3}$ Hyamine 1622 [(diisobutylphenoxyethoxyethyl)dimethylbenzylammonium chloride] of analytical grade purity (Schuchardt, FRG) were prepared by weighing as well as $5 \mathrm{mmol} \mathrm{dm}^{-3}$ stock solutions of cetylpyridinium bromide, pure (Lachema, Brno, Czechoslovakia) in $20 \% \mathrm{v} / \mathrm{v}$ aqueous ethanol.

Isothermally distilled ammonia and water redistilled from quartz apparatus were used. All other reagents were of analytical grade (Panreac, Spain).

\section{Procedure and apparatus}

Solutions of XO, surfactant, buffer and metal solutions were mixed in the order given here. If necessary, the desired acidity was adjusted by hydrochloric acid or ammonia. Resultant solutions containing CPB were $4 \% \mathrm{v} / \mathrm{v}$ in ethanol. As model ions, representing the whole group of REE ions, we used $\mathrm{Y}, \mathrm{La}, \mathrm{Nd}, \mathrm{Dy}$, and $\mathrm{Yb}$, for which detailed measurements were carried out; for the other ones, only limited experiments were performed.

Acidity was measured using a Model 506 pH-meter (Crison, Spain) with combined glass-Ag/AgCl U455-S7 electrode (Ingold, Switzerland). The set was adjusted by means of standard buffers of $\mathrm{pH} 4.0$ and 7.0 (Crison, Spain).

Spectrophotometric measurements were done at ambient temperature on a Model 558 UV-VIS spectrophotometer (Perkin Elmer, FRG) with 10-mm UVpolymethacrylate cuvettes (Nirco, Spain). Water was used as a blank with exception of calibration curve measurements.

\section{Results and Discussion}

Slightly acidic solutions of XO are yellow, showing the maximum absorbance at the wavelength of $435 \mathrm{~nm}$. In the presence of REE cations, intensively red colored complexes with absorption maxima at $570-575 \mathrm{~nm}$ are formed. Because of high color contrast and high reaction rate, $\mathrm{XO}$ is commonly used as a metallochromic indicator for the complexometric titrations of REE.?

As it is shown in Fig. 1, the sensitivity of this reaction can be substantially enhanced in the presence of a surfactant. Among the surfactants we have used, the influence of Hyamine 1622 on the spectrophotometric behavior of REE-XO system is the most weak one. A considerable hyperchromic effect combined with a bathochromic shift of complex absorption maxima to $600-610 \mathrm{~nm}$ was observed when Septonex or CPB was added. However, the high color contrast of the REE$\mathrm{XO}$ reaction was lost because $\mathrm{XO}$ solutions containing CPB or Septonex were green with the absorption maximum at $585 \mathrm{~nm}$. However, the difference between the absorbance of the complex and blank solution is higher in the ternary system than in the absence of surfactant. At the wavelengths of complex absorption maxima, the absorbance values of the blank containing CPB or Septonex are practically identical but absorbance of the complex is higher in the presence of CPB than with Septonex. The shape of absorption curves was practically identical for all the REE examined and only slight differences in positions of absorption maxima were observed (see Table 1).

Absorbance-pH-curves measured at $c(\mathrm{Nd})=0.01 \mathrm{mmol}$ $\mathrm{dm}^{-3}, \quad c(\mathrm{XO}) / c(\mathrm{Nd})=5$ and $c$ (surfact. $) / c(\mathrm{Nd})=10$ in $0.01 \mathrm{~mol} \mathrm{dm}^{-3}$ acetate buffer have shown that in the

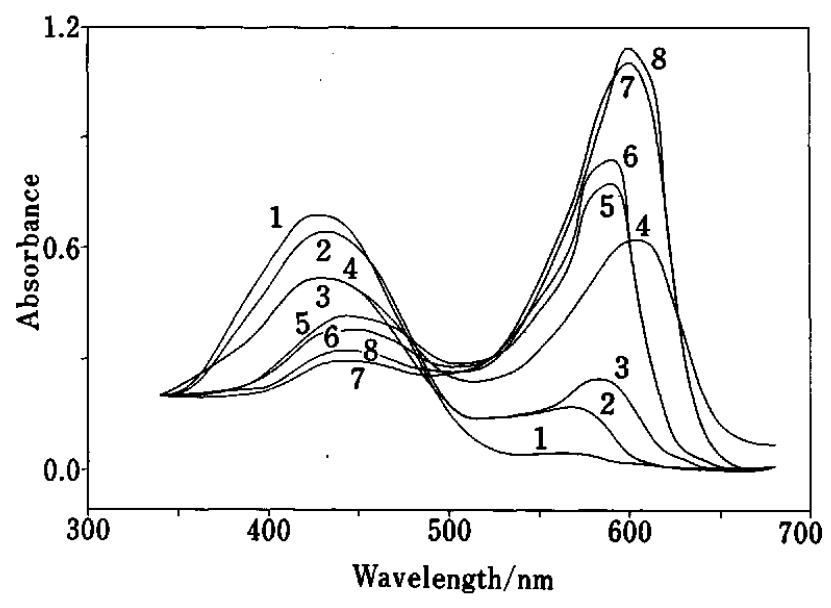

Fig. 1 Absorption spectra of $\mathrm{Nd}(\mathrm{III})-\mathrm{XO}$-surfactant solutions. $\quad c(\mathrm{XO})=0.06 \mathrm{mmol} \mathrm{dm}^{-3}, \quad 0.01 \mathrm{~mol} \mathrm{dm}^{-3}$ acetate buffer, pH 5.50. Curves $1,3,5$, and $6: c(\mathrm{Nd})=0 ; 2,4,7$, and 8: $5 \mu \mathrm{mol} \mathrm{dm}^{-3}$. Curves 1 and 2 were measured in the absence of surfactant; otherwise $0.06 \mathrm{mmol} \mathrm{dm}^{-3}$ of Hyamine 1622 (curves 3, 4), CPB $(5,8)$ or Septonex $(6,7)$ was used. 


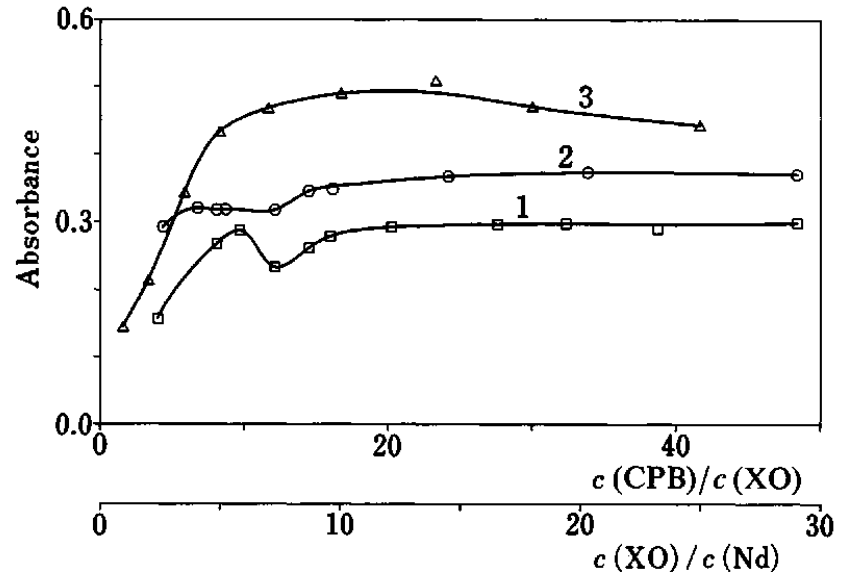

Fig. 2 Dependences of absorbance at $600 \mathrm{~nm}$ on XO or CPB concentration for $\mathrm{Nd}(\mathrm{III})-\mathrm{XO}-\mathrm{CPB}$ system. $\quad 0.01 \mathrm{~mol} \mathrm{dm}^{-3}$ acetate buffer, $\mathrm{pH} 5.50,4 \% \mathrm{v} / \mathrm{v}$ ethanol. Curve $1: c(\mathrm{Nd})=0$; 2 and 3: $5 \mu \mathrm{mol} \mathrm{dm}^{-3}$. Curves 1 and 2: ratio of $c(\mathrm{CPB}) /$ $c(\mathrm{XO})$ at $c(\mathrm{XO})=0.025 \mathrm{mmol} \mathrm{dm}^{-3}$; curve 3: ratio of $c(\mathrm{XO}) /$ $c(\mathrm{Nd})$ at $c(\mathrm{CPB})=0.06 \mathrm{mmol} \mathrm{dm}^{-3}$. In curves 2 and 3, blank absorbance was subtracted.

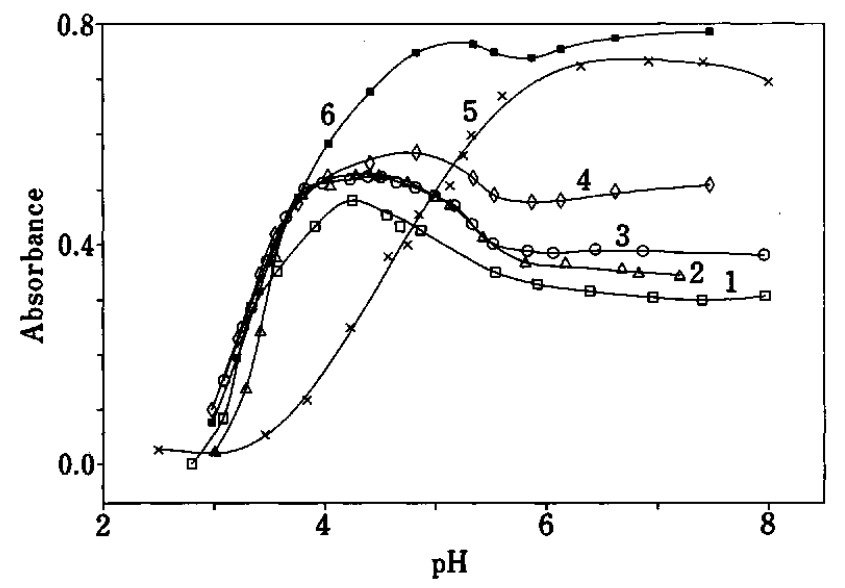

Fig. 3 Absorbance-pH-curves of the REE(III)-XO-CPB system measured at $600 \mathrm{~nm}$ (curves $1-5$ ) and $610 \mathrm{~nm}$ (curve 6). $c(\mathrm{XO})=0.06 \mathrm{mmol} \mathrm{dm}^{-3}, c(\mathrm{CPB})=0.6 \mathrm{mmol} \mathrm{dm}^{-3}$, $c($ acetate $)=0.01 \mathrm{mmol} \mathrm{dm}^{-3}, 4 \% \mathrm{v} / \mathrm{v}$ ethanol. Curve 5: $c(\mathrm{REE})=0$; difference curves $1(\mathrm{Yb}), 2(\mathrm{Y}), 3(\mathrm{Dy}), 4$ and 6 (Nd): $5 \mu \mathrm{mol} \mathrm{dm}^{-3}$.

presence of Septonex the complex formation proceeds at the same acidity as it does without any surfactant, i.e. at $\mathrm{pH}>3.8$. In the solutions containing CPB, the $\mathrm{pH}-$ curve was shifted to a lower acidity range and the complex was already formed at $\mathrm{pH} 2.8$. The maximum values of conditional molar absorptivities of the complex increased from $37000 \mathrm{mmol}^{-1} \mathrm{~cm}^{2}$ in the absence of surfactant (plateau at pH 6.2-6.5) to $61000 \mathrm{mmol}^{-1} \mathrm{~cm}^{2}$ in the presence of Septonex (plateau at pH 5.2-6.5) or to $74000-79000 \mathrm{mmol}^{-1} \mathrm{~cm}^{2}$ in solutions containing CPB (slightly increasing branch at pH 5.2-6.5). The ternary system with $\mathrm{CPB}$ was chosen as the most promising.
The dependences of absorbance on CPB and XO concentrations introduced in Fig. 2 were studied with the aim to optimize reaction conditions. For further experiments, $0.6 \mathrm{mmol} \mathrm{dm}^{-3} \mathrm{CPB}$ and $0.06 \mathrm{mmol} \mathrm{dm}^{-3} \mathrm{XO}$ concentrations were taken as the optimum values.

The influence of acetate buffer concentration on the absorbance of REE-XO-CPB solutions was investigated at $\mathrm{pH} 5.40$ and $c(\mathrm{REE})=5 \mu \mathrm{mol} \mathrm{dm}^{-3}$. Absorbance of the complexes was constant up to $0.02 \mathrm{~mol} \mathrm{dm}^{-3}$ and only a slight decrease was observed up to $0.15 \mathrm{~mol} \mathrm{dm}^{-3}$. However, as higher acetate concentrations were introduced, the absorbance was decreasing rapidly and, in $1.5 \mathrm{~mol} \mathrm{dm}^{-3}$ buffer, no evidence for complex formation was found.

In accordance with the shape of absorbance-pHcurves shown in Fig. 3, we conclude that at least two ternary species are formed in REE-XO-CPB solutions at $\mathrm{pH}>3$. Maximum values of conditional absorptivities were estimated as follows: $153000 \mathrm{mmol}^{-1} \mathrm{~cm}^{2}$ for $\mathrm{Nd}$ at $610 \mathrm{~nm}$ and $\mathrm{pH} 5.3,97000$ for $\mathrm{Yb}(600 \mathrm{~nm}, \mathrm{pH} \mathrm{4.2)}$, 106000 for Dy (605 nm, pH 4.2), and 108000 for $Y$ $(600 \mathrm{~nm}, \mathrm{pH} 4.3)$. These values were obtained as $\varepsilon=\Delta A / c(\mathrm{REE})$ where $\Delta A=A+A_{\mathrm{b}}[c(\mathrm{REE}) / c(\mathrm{XO})-1], A$ is the absorbance of complex solution and $A_{\mathrm{b}}$ means blank absorbance. Generally, the highest absorbance values were reached between $\mathrm{pH} 4$ and $\mathrm{pH} 5$ with the maximum at $\mathrm{pH} 4.4-4.55$, except for $\mathrm{Nd}$ (III) complex solutions (see curve 6 in Fig. 3). For the determination of all the REE studied, the whole acidity range of $\mathrm{pH} 4$ 5 can be recommended as the most convenient, because of both high sensitivity and a relatively low blank absorbance.

Calibration curves were measured under the optimal experimental conditions. The dependences of absorbance on metal concentrations were rectilinear within the range of $c(\mathrm{REE})=0.5-5.0 \mu \mathrm{mol} \mathrm{dm}{ }^{-3}$. At higher con-

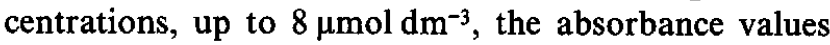
were lower except the values for Y, Tm, and Yb. The results of the data treatment by linear least-squares method are given in Table 1 .

The values of conditional molar absorptivities measured at $600 \mathrm{~nm}$ are very similar for all REE, i.e. in the range of $80000-93000 \mathrm{mmol}^{-1} \mathrm{~cm}^{2}$. At 610 and $620 \mathrm{~nm}$ the differences among the molar absorptivities are higher with the values of $77000-127000$ and $56000-$ $113000 \mathrm{mmol}^{-1} \mathrm{~cm}^{2}$. All the curves give high correlation coefficients $r_{x y}=0.9984-0.9999$ (0.9996 in average) and negligible $A_{0}$ intercept. The values of standard deviation $s_{0}=0.001-0.009$ are comparable with the photometric accuracy of absorbance measurements, which was \pm 0.005 absorbance units. Limits of detection given as $\mathrm{LOD}=3 s_{0} / \varepsilon$ are within the range of 0.04 $0.33 \mu \mathrm{mol} \mathrm{dm}^{-3}$, however, the lowest values were reached at $610 \mathrm{~nm}$ where $L O D=0.04-0.20 \mu \mathrm{mol} \mathrm{dm}{ }^{-3}$. The complex formation proceeds immediately after mixing of the solutions and the absorbance values are constant within a five hour period.

Xylenol Orange is a typical low selectivity reagent, most heavy metals interfere in the determination of REE 
Table 1 Statistical parameters of calibration curves of rare earth elements with Xylenol Orange and cetylpyridinium bromide at $\mathrm{pH} 4.50$

\begin{tabular}{|c|c|c|c|c|c|c|c|c|c|c|}
\hline \multirow{2}{*}{ Ion } & \multicolumn{3}{|c|}{$600 \mathrm{~nm}$} & \multicolumn{3}{|c|}{$610 \mathrm{~nm}$} & \multicolumn{3}{|c|}{$620 \mathrm{~nm}$} & \multirow{2}{*}{$\lambda_{\max }{ }^{d}$} \\
\hline & $100 A_{0}{ }^{\mathrm{a}}$ & $\varepsilon^{\mathrm{b}}$ & $\operatorname{LOD}^{\mathrm{c}}$ & $100 A_{0}{ }^{\mathrm{a}}$ & $\varepsilon^{\mathbf{b}}$ & $\operatorname{LOD}^{c}$ & $100 A_{0}^{\mathrm{a}}$ & $\varepsilon^{\mathbf{b}}$ & $\mathrm{LOD}^{c}$ & \\
\hline $\mathrm{Y}$ & $-1.3 \pm 0.7$ & $8.29 \pm 0.23$ & 0.33 & $-1.4 \pm 0.4$ & $8.33 \pm 0.13$ & 0.18 & $-1.3 \pm 0.3$ & $5.75 \pm 0.11$ & 0.26 & 607 \\
\hline $\mathbf{L a}$ & $0.6 \pm 0.2$ & $9.21 \pm 0.06$ & 0.07 & $1.2 \pm 0.3$ & $12.58 \pm 0.08$ & 0.07 & $0.7 \pm 0.2$ & $10.57 \pm 0.06$ & 0.06 & 612 \\
\hline $\mathrm{Ce}$ & $0.9 \pm 0.3$ & $8.57 \pm 0.09$ & 0.11 & $1.5 \pm 0.4$ & $11.98 \pm 0.12$ & 0.13 & $1.0 \pm 0.2$ & $10.70 \pm 0.08$ & 0.08 & 613 \\
\hline Pr & $0.5 \pm 0.3$ & $8.89 \pm 0.10$ & 0.13 & $1.3 \pm 0.5$ & $12.41 \pm 0.15$ & 0.15 & $0.8 \pm 0.3$ & $10.99 \pm 0.10$ & 0.11 & 613 \\
\hline $\mathrm{Nd}$ & $0.4 \pm 0.3$ & $9.22 \pm 0.10$ & 0.13 & $1.1 \pm 0.4$ & $12.74 \pm 0.12$ & 0.12 & $0.7 \pm 0.2$ & $11.33 \pm 0.07$ & 0.08 & 613 \\
\hline $\mathrm{Sm}$ & $0.7 \pm 0.4$ & $8.82 \pm 0.12$ & 0.17 & $1.1 \pm 0.4$ & $12.19 \pm 0.14$ & 0.15 & $0.6 \pm 0.2$ & $10.86 \pm 0.07$ & 0.08 & 613 \\
\hline $\mathrm{Eu}$ & $1.1 \pm 0.4$ & $9.26 \pm 0.12$ & 0.16 & $1.6 \pm 0.6$ & $12.29 \pm 0.19$ & 0.20 & $1.1 \pm 0.4$ & $10.80 \pm 0.12$ & 0.14 & 613 \\
\hline $\mathrm{Gd}$ & $0.6 \pm 0.4$ & $9.06 \pm 0.14$ & 0.20 & $1.1 \pm 0.5$ & $11.54 \pm 0.15$ & 0.16 & $0.5 \pm 0.2$ & $9.85 \pm 0.07$ & 0.09 & 611 \\
\hline $\mathrm{Tb}$ & $0.2 \pm 0.7$ & $8.90 \pm 0.24$ & 0.30 & $0.9 \pm 0.4$ & $10.14 \pm 0.14$ & 0.15 & $0.1 \pm 0.1$ & $8.08 \pm 0.04$ & 0.07 & 610 \\
\hline Dy & $0.7 \pm 0.5$ & $8.62 \pm 0.17$ & 0.24 & $0.3 \pm 0.2$ & $9.28 \pm 0.06$ & 0.06 & $-0.5 \pm 0.2$ & $6.84 \pm 0.06$ & 0.09 & 608 \\
\hline Ho & $1.2 \pm 0.5$ & $8.56 \pm 0.16$ & 0.21 & $0.6 \pm 0.2$ & $8.68 \pm 0.07$ & 0.10 & $-0.3 \pm 0.2$ & $6.03 \pm 0.06$ & 0.10 & 606 \\
\hline Er & $0.6 \pm 0.4$ & $8.50 \pm 0.13$ & 0.18 & $0.05 \pm 0.2$ & $8.32 \pm 0.06$ & 0.07 & $-0.8 \pm 0.3$ & $5.57 \pm 0.10$ & 0.22 & 605 \\
\hline $\mathrm{Tm}$ & $0.5 \pm 0.6$ & $8.34 \pm 0.19$ & 0.25 & $0.02 \pm 0.2$ & $8.11 \pm 0.08$ & 0.11 & $-0.7 \pm 0.2$ & $5.35 \pm 0.06$ & 0.11 & 604 \\
\hline $\mathbf{Y b}$ & $1.2 \pm 0.5$ & $8.10 \pm 0.16$ & 0.22 & $0.5 \pm 0.1$ & $7.86 \pm 0.02$ & 0.04 & $-0.5 \pm 0.3$ & $5.23 \pm 0.09$ & 0.23 & 605 \\
\hline $\mathbf{L u}$ & $0.6 \pm 0.4$ & $7.96 \pm 0.12$ & 0.19 & $-0.1 \pm 0.1$ & $7.72 \pm 0.05$ & 0.08 & $-0.9 \pm 0.3$ & $5.12 \pm 0.10$ & 0.23 & 605 \\
\hline
\end{tabular}

$c(\mathrm{XO})=0.06 \mathrm{mmol} \mathrm{dm}^{-3} ; c(\mathrm{CPB})=0.6 \mathrm{mmol} \mathrm{dm}^{-3} ; c(\mathrm{REE})=0.5-5.0 \mu \mathrm{mol} \mathrm{dm}-3 ; 0.01 \mathrm{~mol} \mathrm{dm}^{-3}$ acetate buffer; each curve is constructed of 6 points, absorbance is measured against blank. a. $A_{0}: y$-intercept. b. Conditional molar absorptivities in $\mathrm{m}^{2} \mathrm{mmol}^{-1}$. c. Limit of detection $\mathrm{LOD}=3 s_{0} / \varepsilon$ in $\mu \mathrm{mol} \mathrm{dm}{ }^{-3}$. d. Measured at $c(\mathrm{REE})=5.0 \mu \mathrm{mol} \mathrm{dm}^{-3}$.

Table 2 The effect of some ions on the determination of Nd(III) with Xylenol Orange and cetylpyridinium bromide

\begin{tabular}{lcclcccrrr}
\hline Ion & $\mathrm{ppm}^{\mathrm{a}, \mathrm{b}}$ & $\mathrm{ppm}^{\mathrm{a}, \mathrm{c}}$ & $\mathrm{Ion}$ & $\mathrm{ppm}^{\mathrm{a}, \mathrm{b}}$ & $\mathrm{ppm}^{\mathrm{a}, \mathrm{c}}$ & $\mathrm{Ion}$ & $\mathrm{ppm}^{\mathrm{a}, \mathrm{b}}$ & $\mathrm{ppm}^{\mathrm{a}, \mathrm{c}}$ \\
\hline $\mathrm{Fe}^{2+}$ & 0.3 & 0.4 & $\mathrm{Mn}^{2+}$ & 4.7 & 12.9 & $\mathrm{Ba}^{2+}$ & 2.6 & 7.1 \\
$\mathrm{Fe}^{3+}$ & 0.2 & 0.3 & $\mathrm{~Pb}^{2+}$ & 0.8 & 12.8 & $\mathrm{Sr}^{2+}$ & 84.8 & 86.4 \\
$\mathrm{Co}^{2+}$ & 0.2 & 2.1 & $\mathrm{Cr}^{3+}$ & 7.3 & 25.9 & $\mathrm{NO}_{3}{ }^{-}$ & 11.3 & 26.7 \\
$\mathrm{Ni}^{2+}$ & 0.1 & 0.5 & $\mathrm{UO}_{2}^{2+}$ & 1.4 & 1.0 & $\mathrm{SO}_{4}^{2-}$ & 5.8 & 13.3 \\
$\mathrm{Cu}^{2+}$ & 0.9 & 0.2 & $\mathrm{Mg}^{2+}$ & 3.0 & 7.3 & $\mathrm{C}_{2} \mathrm{O}_{4}^{2-}$ & 2.2 & 2.9 & $\mathrm{H}_{2}^{2-}$ \\
$\mathrm{Zn}^{2+}$ & 1.4 & 0.2 & $\mathrm{Ca}^{2+}$ & 4.3 & 9.8 & $\mathrm{H}_{2} \mathrm{Y}^{2-\mathrm{d}}$ & 0.9 & 1.0 \\
\hline
\end{tabular}

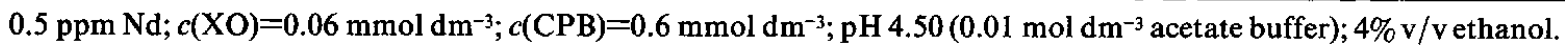
At the measurement of the cation effects, the effect of amount of anion added on Nd complex absorbance was estimated using the sodium salt of this anion and subtracted. a. Ion concentration changing the value $A-A_{\mathrm{b}}$ (absorbances of Nd complex and blank solutions) by $2 \%$ rel. b. Measured at $600 \mathrm{~nm}$. c. $620 \mathrm{~nm}$. d. Dihydrogen ethylenediaminetetraacetate.

with XO and CPB. The limiting concentrations of some ions for the determination of $0.5 \mathrm{ppm} \mathrm{Nd}$ are given in Table 2.

In comparison with the previous spectrophotometric methods based on the reaction of REE with XO and $\mathrm{CPB}^{2-4}$, significantly higher values of molar absorptivities and lower detection limits were found after optimization of reaction conditions. Both, molar absorptivities and detection limits are better by a factor of 1.1 to 1.6 and of 3 to 10 than the values introduced ${ }^{6}$ for Chrome Azurol S in the presence of CPB as the best one from several reagents used for REE determination. The reaction in slightly acidic media also has the advantage of lower blank absorbance and, in the case of possible application to HPLC postcolumn derivatization, better compatibility with acidic effluent. ${ }^{8}$ The results obtained in this work represent a systematic investigation of the parameters influencing the reaction and can be applied to photometric detection of rare earths.

The present work has been carried out under the CICYT (Spanish Commission for Research and Development) financial support, project No. PTR 89-0206. Dr. A. Hrdlicka acknowledges the Spanish Ministry of Education and Science for financing his stay at U.A.B. (Química Analítica).

\section{References}

1. P. Vácha and J. Vrbský, Sbornik Vys. Shk. Khim. Tekhnol. [Prague], 1989, H23, 35.

2. V. Svoboda and V. Chromý, Talanta, 13, 237 (1966).

3. M. Otomo and Y. Wakamatsu, Bunseki Kagaku, 17, 764 (1968); Chem. Abstr., 69, 73698 (1968).

4. V. V. Belousova, R. K. Chernova and L. K. Sachova, Zav. Lab., 44, 390 (1978).

5. G. P. Svistunova and V. G. Amelin, Zh. Anal. Khim., 43, 
1994 (1988).

6. D. B. Gladilovich, V. Kubán and L. Sommer, Talanta, 35, 259 (1988).

7. R. Pr̛ibil, Talanta, 12, 925 (1965); 14, 619 (1967).

8. K. Robards, S. Clarke and E. Patsalides, Analyst
[London], 113, 1757 (1988).

(Received July 29, 1991)

(Accepted October 17, 1991) 